\title{
Bir Türkiye Populasyonunda BDNF Geni Val66Met Polimorfizmi ile Obezite iliş̧kisinin Analizi: Olgu Kontrol Çalışması
}

\author{
Association Analysis of the BDNF Val66Met Variation with Obesity in a Population from Turkey: A \\ Case Control Study \\ Ahmet BEŞTEPE ${ }^{1}$, Mehmet Ali SÖZEN² ${ }^{2}$ Abdurrahman GENÇ ${ }^{3}$, Kağan ÜÇOK ${ }^{3}$ Lütfi AKGÜN $^{4}$, Kuyaş \\ HEKIMLER ÖZTÜRK', Necat IMIRZALIOĞLU' \\ ${ }^{1}$ Afyon Kocatepe Üniversitesi Tıp Fakültesi, Tıbbi Genetik AD, Afyonkarahisar \\ ${ }^{2}$ Afyon Kocatepe Üniversitesi Tıp Fakültesi, Tıbbi Biyoloji AD, Afyonkarahisar \\ ${ }^{3}$ Afyon Kocatepe Üniversitesi Tıp Fakültesi, Fizyoloji AD, Afyonkarahisar \\ ${ }^{4}$ Afyonkarahisar Devlet Hastanesi, Obezite Kliniği, Afyonkarahisar
}

\begin{abstract}
öz
Amaç: Obezite karmaşık etyolojisi ile dünya çapında epidemik bir sağlık problemi haline gelmektedir. Birçok farklı genetik ve çevresel faktörler obezite gelişimine katkıda bulunmaktadır. Bu çalışmada, bir Türkiye populasyounda BDNF geni Val66Met varyantı ile obezite ve obezite-ilişkili klinik fenotipler arasında ilişki olup olmadığının araştırılması amaçlanmıştır.
\end{abstract}

Gereç ve Yöntem: Çalışmaya toplam 168 birey (88 obez olgu ve 80 sağlıklı kontrol) alındı. Klinik değerlendirilmesi yapılan katılımcılara antropometrik ölçüm ve vücut kompozisyon analizi yapıldı. BDNF geni Val66Met polimorfizmine ilişkin genotipleme çalışması PCR-RFLP tekniği kullanılarak yapıldı. Elde edilen ilgili polimorfizme ait genotipler ile alel frekansları ve antropometrik ölçüm sonuçlarının istatistiksel değerlendirmesi bilgisayar ortamında SPSS programı kullanılarak yapıldı.

Bulgular: Çalışılan polimorfizme ait (BDNF Val66met,) genotip ve aleller ile obezite ve obezite-ilişkili fenotipler arasında obez ve kontrol grubu arasında istatistiksel olarak anlamlı bir fark bulunmadı.

Sonuç: Bu bulgular çalışılan polimorfizmin obezite ve obezite-ilişkili fenotiplerin gelişiminde yatkınlık oluşturucu bir role sahip olduğu olgusunu desteklememektedir. Bununla beraber, ilgili polimorfizmin obezite gelişimindeki katkısını netleştirmek için daha geniş populasyon serilerinde bir çok aday gen ve polimorfizmlerin birlikte değerlendirildiği yeni çalışmaların yapılması gerektiği kanaatindeyiz.

Anahtar Kelimeler: Obezite; BDNF geni Val66Met polimorfizmi; ilişkilendirme.

\section{ABSTRACT}

Objective: Obesity is becoming the epidemic health problem worldwide with a very complex etiology. The interaction between diverse genetic and environmental factors contributes to development of obesity. In this tudy, it was aimed to investigate the association/s between BDNF gene Val66Met variant and obesity as well as obesityrelated clinical phenotypes in a population from Turkey.

Material and Methods: A total of 168 subjects ( 88 obese cases and 80 non-obese healthy controls) were included in this study. Following the clinical evalution, the subjects were assessed for anthropometric measurement and body composition analyses. Genotyping of BDNF Val66Met polymorphism was carried out using polymerase chain reaction-restriction fragment length polymorphism technique. Then the genotypic and allele frequencies as well as anthropometric measurement were analyzed statisitically using SPSS program.

Results: The results revealed no significant difference between BDNF Val66Met polymorphism and obesity or obesity-related clinical phenotypes in ceses versus controls.

Conclusion: These results do not support a predisposing role of BDNF Val66Met polymorphism in the developemnt of obesity or obesity realted clinical phenotypes. However, to confirm that the gene variant contributes to obesity and obesity-related phenotypes, further studies with both higher population sizes and many candidate genes are needed to be investigated simultaneously.

Keywords: Obesity; brain-derived neurotrophic factor Val66Met polimorphism; association. 


\section{Gíriş}

Beyin-kökenli nörotrofik faktör (BDNF), merkezi sinir sisteminin farklılaşmasında çok kritik iş gördüğü bilinen bir faktördür. Heterozigot ve şartlı nakavt farelerde kuşaklar boyu gösterildiği üzere, BDNF aynı zamanda obezite ve lokomotor aktivitede de rol oynar. Bu fareler, agresiflik ve lokomotor aktivite bozukluklarının da eşlik ettiği olgunlukta ortaya çıkan obezite fenotipi geliştirirler (1-3). Yakın zamanlarda, obez olan bir hastada BDNF'yi kodlayan gende bir mutasyon belirlendi (4). Gray ve meslektaşları BDNF genini içine alan bölgenin kromozomal inversiyonunu taşıyan hiperfaji ve obeziteli bir hasta tanımladılar (5). Ayrıca, BDNF reseptörü olan TrkB'de bir mutasyonun obezite fenotipi ile ilişkili olduğu gösterildi $(6,7)$. Bazı kohortlarda da BDNF yeme bozuklukları ile de ilişkilendirilmiştir (8-10).

BDNF geninde bulunan bir Tek Nükleotid Polimorfizmi (TNP) (Val66Met) ile obezite arasında daha önceki bir çalışmada Alman populasyonunda bir ilişki bulunamamasına rağmen (4), Belçika populasyonunda kadınlarda 66Met aleli ile bir ilişki olduğu gösterilmiştir (11). Yakın zamanlarda yapılan başka iki çalışmadan birinde ilgili polimorfizm ile sağlıklı erşkinlerde zaman içindeki Beden Kütle İndeksi (BKI) değişimleri arasında bir ilişki bulunamazken (12), diğerinde ise ilgili genin kod bölgesinde mutasyon taraması yapılmış ve net bir kauzatif varyant tesbit edilememiştir (13). Bu çalışmada obezite gelişimine yatkınlıkta rol oynadığı varsayılan BDNF geni Val66Met (rs6265) polimorfizmi ile obezite ve obezite-ilişkili klinik fenotipler ve vücut kompozisyon ölçümleri arasındaki ilişkilerin araştırılması planlanmıştır. Böylece söz konusu polimorfizmin obezite gelişimine etkisinin aydınlatılması amaçlanmıştır.

Mevcut çalışmada, bizBDNFgenindekiVal66Met polimorfizminin obezite patogenezinde rol oynayabileceği hipotezini kurduk. Bu sebeple, obez ve obez olmayan kontrol grubunun genotiplemesini gerçekleştirmek ve ilgili varyantın genotip dağılımları ve alel frekanslarının karşılaştırmalı analizini yapmak amacıyla ilgili gen varyantı ile obezite arasında ilişki olup olmadığını araştırmak için bu olgu kontrol çalışmasını planladık.

\section{GEREÇ ve YÖNTEM}

Afyonkarahisar Devlet Hastanesi Obezite kliniğine müracaat eden seksen-sekiz obez erişkin (ortalama BKi $35.7 \pm 5.2 \mathrm{~kg} / \mathrm{m}^{2}$ ) çalışmaya dahil edildi. Çalışma kriterleri başlıca obezite (BKi $30 \mathrm{~kg} / \mathrm{m}^{2}$ ) ve yaş (35 ila 70 arası) idi. Diyabetli veya normal olmayan glukoz toleransı olan hastalar çalışmaya alınmadı. Diğer dışlama kriterleri ise hamilelik, Cushing hastalığı ve hipo- ya da hipertiroidizm idi.

Kontrol bireyler (80 obez olmayan; ortalama BKi 22.6 $\pm 2.5 \mathrm{~kg} / \mathrm{m}^{2}$ ) Afyonkarahisar Devlet Hastanesi Obezite Kliniği ve Üniversite Hastanesi çalışanları arasında ve Afyon bölgesi halkından seçilen kişilerdi. Çalışmaya katılanların hepsi beyaz ve hiçbiri kilo kontrolü için bir program kapsamında değildi. Çalışma protokolü Yerel Etik Komite tarafından onaylanmış ve bütün katılımcılardan gönüllülük esasına dayalı gönüllü onam formu alındı.

Fizyolojik ölçümler Afyon Kocatepe Üniversitesi Tıp Fakültesi Spor Fizyolojisi Bilim Dalı Laboratuvarında yapıldı. Boy en yakın $0.5 \mathrm{~cm}$ hassasiyetinde ölçüldü; vücut kilosu dijital terazi ile 0.1 kg hassasiyetinde ölçüldü. BKI değeri, kilo $(\mathrm{kg})$ boyun $(\mathrm{m})$ karesine bölünerek hesaplandı. Vücut yağ yüzdesi biyoelektirik empedans analiz sistemiyle (Bodystat 1500, Bodystat Ltd., Douglas, Isle of Man, UK) gerçekleştirildi (14). Bel ve kalça çevre ölçümleri standardize bölgelerden mezura ile yapıldı ve bel/kalça oranı hesaplandı (15).

BDNF genindeki Val66Met polimorfizminin (rs6265) genotiplenmesi PCR-RFLP metodu ile yapıldı. Bunun için önce olgu ve kontrol bireylere ait periferik venöz tam kan örneklerinden NucleoSpin ${ }^{\circledR}$ (Macherey-Nagel, Germany) kiti kullanılarak genomik DNA elde edildi. PCR standard şartlarda üretici firmaların tavsiyeleri doğrultusunda şu primerler (16) kullanılarak (ileri primer $\mathrm{F} 5^{\prime} \mathrm{CTG}$ GAG AGC GTG AAT GGG CC 3've Geri primer R 5'TCC AGC AGA AAG AGA AGA GGA GGC 3') gerçekleştirildi (Taq DNA Polimeraz BioRon ve Pml I restriksion enzimi de Fermentas firmasından). Amplifikasyonlar Eppendorf marka PCR cihazında yapıldı. (Roche, Penzberg, Germany). Enzim kesimi durumunda 70-136 bç'lik bantlar, kesmeme durumunda ise tek 206 bç'lük bant elde edildi (Şekil 1). 
Olgular ile kontroller arasındaki genotip dağılımlarını kıyaslamak için $\times 2$ kare testi, alel frekanslarını kıyaslamak için de Fisher testi kullanıldı. Bu analizleri takiben, genotiplere göre

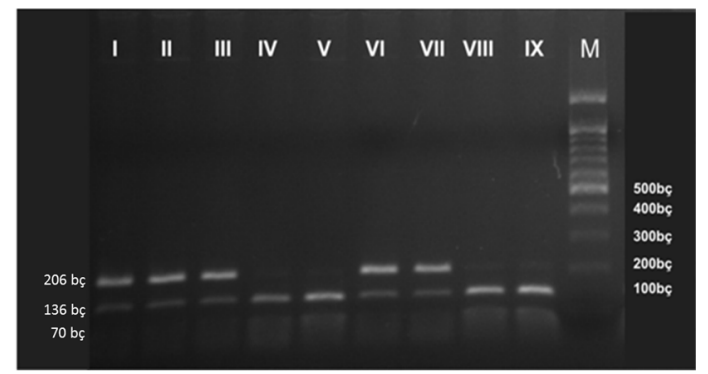

Şekil I: BDNF Geni Val66Met polimorfizmini içeren PCR amplifikasyon ürününün Pmll restriksiyon enzimi ile yapılan enzim kesimi sonrası \% 2'lik agaroz jeldeki görüntüsü. Enzim kesimi sonucunda 70-136 bç'lik bantlar, kesmeme durumunda ise tek 206 bç'lük bant görülmektedir I-IX olgulara ait Pm1l enzim kesim ürünleri (1: GA II: GA, III: GA, IV: GG, V: GG, VI: GA, VII: GA, VIII: GG, IX: GG), M: Marker, G: Yabanil tip, A: Mutant tip.

(GG, GA ve AA) antropometrik değerlerde her iki grupta bir farklılık olup olmadığını görmek için Kruskal Wallis testi kullanıldı. Anlamlılık düzeyi olarak $p=0.05$ kabul edildi. İstatistiksel analizlerden $\mathrm{x} 2$ kare ve Fisher testi için web bazlı programlar Kruskal Wallis testi için ise SPSS versiyon 12.0 kullanıldı (SPSS, Chicago, IL, USA). Hardy-Weinberg dengesini test için web bazlı HWE programı kullanıldı (http://www. had2know.com/academics/hardy-weinbergequilibrium-calculator-2-alleles.html).

\section{BULGULAR}

Evvela, Val66Met polimorfizminin HardyWeinberg dengesi içinde olup olmadığını kontrol ettik ve ilgili polimorfizm bu bakımdan dengede idi. Genotiplemeyi müteakip, obez olgularda ve obez olmayan kontrollerde genotip dağılımları ve alel frekansları arasında fark olup olmadığına bakıldı. Genotip dağılımları (GG, GA ve $A A$ ) olgularda ayrı ayrı $\% 68,2, \% 27,2$, ve $\%$ 0,045 olarak ve kontrollerde ise $\% 67,5, \% 31,2$, ve $\% 0,012$ olarak bulundu ki hesaplanan $\times 2$ kare (odd ratio) 0.06 ve $p$ değeri 0.806 idi. Bunun yanısıra, 66Met alel frekansı obez olgularda \% 18,2 ve kontrollerde $\% 16,8(p=0.109)$ bulundu (Tablo 1). Böylece, BDNFVal66Met polimorfizmi ile obezite arasında bir ilişki bulunmadı.

Daha sonra antropometrik veriler genotiplere göre (GG, GA ve $A A$ ) analiz edildiğinde (Tablo 2), olgu grubunda ayrı ayrı bel çevresi ortalama değerlerinde (97.4 $\pm 10.5,98.3 \pm 10.4$, 90.8 \pm 6.5$)$ AA genotiplilerde belirgin bir düşüş olduğu; kalça çevresi ortalama değerlerinde
Tablo I: Obez olgular ve kontrol grubunda BDNF geni Val66Met polimorfizmi genotip dağıımları ve alel frekansları.

\begin{tabular}{|c|c|c|c|c|c|c|c|c|c|}
\hline & \multicolumn{3}{|c|}{ Genotip* } & \multicolumn{6}{|c|}{${\text { Ale }{ }^{*}}^{*}$} \\
\hline & $n$ & GG & GA & AA & $\chi^{2}$ & $P$ & G & A & $P$ \\
\hline Obez & 89 & 60 & 24 & 4 & & & 144 & 32 & \\
\hline Olgular & & $(0.682)$ & $(0.272)$ & $(0.045)$ & & & $(0.818)$ & $(0.182)$ & \\
\hline Kontroller & 80 & $\begin{array}{c}54 \\
(0.675)\end{array}$ & $\begin{array}{c}25 \\
(0.312)\end{array}$ & $\begin{array}{c}1 \\
(0.012)\end{array}$ & 0.06 & 0.806 & $\begin{array}{c}133 \\
(0.831)\end{array}$ & $\begin{array}{c}27 \\
(0.168)\end{array}$ & 0.109 \\
\hline
\end{tabular}

*Genotip ve alel verileri rakam ve yüzdelik oran olarak sunulmuștur. Genotip $P$-değerleri $\chi^{2}(2 \mathrm{df})$ ve alel frekansları P-değerleri ise Fisher testi (1-yönlü) ile hesaplanmıştır. Çalışmada $(p<0,05)$ istatistiksel olarak

(112.2 $\pm 10.1, \quad 113.7 \pm 11.5, \quad 109.8 \pm 6.7) \quad$ AA genotiplilerde hafif bir düşüş olduğu; bel/kalça oranları $(0.8 \pm 0.0,0.8 \pm 0.0,0.8 \pm 0.0)$, yüzdelik yağ $(38.8 \pm 9.3,40.4 \pm 10.7,40.8 \pm 9.6)$ ve BKI ortalama değerlerinde $(35.6 \pm 5.1,35.9 \pm 5.6,34.6 \pm 4.2)$ bariz bir fark olmadığı gözlemlendi. Kontrol grubunda ise, ayrı ayrı bel çevresi ortalama değerlerinde $(74.2 \pm 8.1,73.2 \pm 6.8,73.0 \pm 6.5)$ ve bel/kalça oranları ortalama değerlerinde $(0.8 \pm 0.0,0.8 \pm 0.0,0.8 \pm 0.0)$ bariz bir farka rastlanmazken; yüzdelikyağ $(22.9 \pm 7.6,24.1 \pm 7.8$,

Tablo II: Çalışılan populasyonda BDNF geni Val66Met polimorfizmi genotiplerine göre olgu ve kontrol grubunun antropometrik ölçüm değerlerinin dağılımı.

\begin{tabular}{|c|c|c|c|c|c|c|c|c|}
\hline \multicolumn{3}{|c|}{ Obez grubu $(n=88)$} & \multicolumn{6}{|c|}{ Kontrol grubu (n=80) } \\
\hline & $\begin{array}{c}\mathrm{GG} \\
(\mathrm{n}=60)\end{array}$ & $\begin{array}{c}\text { GA } \\
(n=24)\end{array}$ & $\begin{array}{c}\text { AA } \\
(n=4)\end{array}$ & $\mathrm{p}$ & $\begin{array}{c}G G \\
(n=54)\end{array}$ & $\begin{array}{c}\text { GA } \\
(n=25)\end{array}$ & $\begin{array}{c}\text { AA } \\
(n=1)\end{array}$ & $\mathrm{p}$ \\
\hline $\begin{array}{l}\text { Bel çevresi } \\
(\mathrm{cm})\end{array}$ & $97,4 \pm 10,5$ & $98,3 \pm 10,4$ & $90,8 \pm 6,5$ & 0,293 & $74,2 \pm 8,1$ & $73,2 \pm 6,8$ & 73,0 & 0,816 \\
\hline $\begin{array}{l}\text { Kalça çevresi } \\
(\mathrm{cm})\end{array}$ & $112,2 \pm 10,1$ & $113,7 \pm 11,5$ & $109,8 \pm 6,7$ & 0,759 & $93,4 \pm 5,5$ & $92,6 \pm 5,0$ & 105,0 & 0,228 \\
\hline $\begin{array}{l}\text { Bel/kalça } \\
\text { oranı }\end{array}$ & $0,8 \pm 0,0$ & $0,8 \pm 0,0$ & $0,8 \pm 0,0$ & 0,729 & $0,7 \pm 0,0$ & $0,7 \pm 0,0$ & 0,7 & 0,437 \\
\hline Yağ $(\%)$ & $38,8 \pm 9,3$ & $40,4 \pm 10,7$ & $40,8 \pm 9,6$ & 0,827 & $22,9 \pm 7,6$ & $24,1 \pm 7,8$ & 30,9 & 0,417 \\
\hline $\mathrm{BKi}\left(\mathrm{kg} / \mathrm{cm}^{2}\right)$ & $35,6 \pm 5,1$ & $35,9 \pm 5,6$ & $34,6 \pm 4,2$ & 0,969 & $22,6 \pm 2,6$ & $22,4 \pm 2,4$ & 26,7 & 0,229 \\
\hline
\end{tabular}

*Genotiplere göre verilen fenotipik değerler rakam \pm standart sapma olarak sunulmuștur. $P$-değerleri Kruskal Wallis testi ile hesaplanmışıtı. Çalışmada $(p<0,05)$ istatistiksel olarak anlamlı kabul edildi.

30.9 \pm 9.6$)$ ve BKi ortalama değerlerinde $(22.6 \pm 2.6,22.4 \pm 2.4,26.7 \pm 0.0)$ AA genotiplilerde hafif bir artış olduğu; kalça çevresi ortalama değerlerinde ise $(93.4 \pm 5.5,92.6 \pm 5.0,105.0 \pm 0.0)$ AA genotiplilerde belirgin bir artış olduğu gözlemlendi.

\section{TARTIŞMA}

BDNF'nin obezite'deki potansiyel rolü ilk defa KO farelerin obez fenotip göstermeleri ile gösterildi (1-3). Bunu 2003'de, BDNF melanokortin-4 reseptörünün aşağısında iş gördüğü ve onun besin alımı üzerindeki etkisi TrkB reseptörünün aktivasyonu aracılığıyla düzenlendiği olgusu takip etti (17). Takiben, yapılan mutasyon analizleri obez hastalarda $B D N F$ ve TrkB mutasyonları olduğunu ortaya çıkardı (4- 7). 
$\mathrm{Bu}$ çalışmaların bir kısmı, BDNF Val66Met polimorfizminingıdaalımının düzenlenmesinde bir role sahip olabileceğini önermişlerdir. Bazı populasyonlarda ve belli çalışma gruplarında ve cinsiyetlerde gözlemlenen ilişki şans eseri olabileceği gibi, asıl yol açan SNP ile yüksek linkaj dengesizliğinden dolayı da olabileceği ve Val66Met (rs6265) polimorfizminin adı geçen ilişkilerden sorumlu en güçlü işlevsel varyant (TNP) olabileceği değerlendirilmiştir (18). Buna delil olarak bazı çalışmalarda 66Met alelinin sinir hücrelerinde BDNF öncü proteininin (proBDNF) hücre içi trafiğini ve salgılanmasını etkilediğini göstermiştir (19, 20). Bunun yanısıra, 66Met alelinin proBDNF'nin olgun BDNF'ye kesimini önleyebileceği de önerilmiştir (21). Buna bağlı olarak, 66Met alelinin proBDNF'nin olgun BDNF'ye azalan kesimine yol açabileceği ve proBDNF gıda alımının düzenlenmesine karıştığı düşünülen TrkB reseptörü yerine p75NTR reseptörüne tercihen bağlandığından dolayı (22), azalan olgun BDNF'nin miktarı gıda alımının inhibisyonunun daha az olmasına yol açmasını bekleyerek en nihayetinde obeziteye yol açabileği hipotezi üzerinde de durulmuştur.

Değişik populasyonlarda yapılan genetik ilişkilendirme çalışmalarının bazıları BDNF Val66Met polimorfizminin varsayılan rolünü destekler mahiyetinde veriler ortaya koyarken $(11,23-27)$, diğer bazı çalışmalar ise bu rolü desteklemeyen bulgular sunmuşlardır (4, 12, $13,28,29)$. BDNFVal66Met variantları ile obezite veya BKI arasında ilişki bulan çalışmalardaki bulgular da çelişkilidir ki bazılarında Met aleli $(11,25)$, bazılarında ise Val aleli $(23,24,26)$ obezite ile ilişkili bulunmuştur. Bizim sonuçlar ise ilişki bulunmayan Almanya, İspanya, Hırvatistan ve Belçika gibi beyaz Avrupa kökenli populasyonlarda elde edilen bulgularla uyumludur $(4,12,13,28,29)$.

Örneğin, Friedel ve meslektaşlarının çalışmasında Val66Met varyantının obezitedeki potansiyel rolü araştırılmış, aşırı obez çocuklar ve ergenler kontroller ile kıyaslanmış fakat anlamlı bir farklılık saptanmamıştır (4). Bu farklılık birinde çocuk ve ergenlerin ve diğerinde ise sadece obez yetişkin kadınların çalışılmasından kaynaklanabilir. Aynı zamanda cinsiyete özgü bir etkinin mevcudiyeti de söz konusu olabilir. Ayrıca, heterozigot BDNF KO farelerinde olgun yaşta geç-ortaya çıkan obezite fenotipinin görülmesi (1-3), Met alelinin etkisinin çocukları çalışırken görülemeyebileceğini de akla getirmektedir.

Bizim çalışmamı ise BDNF Val66Met polimorfizminin ne obezite ve ne de BKI artışı gibi obezite ilişkili fenotiplerle ilişkili olduğu hipotezini desteklememiştir. Bu bulgulara dayalı olarak BDNF Val66Met polimorfizminin en azından çalışılan Türkiye populasyonunda obezite patogenezinde önemli bir işlevi olduğunu göstermemektedir. Bu bakımdan mevcut çalışma önceki bazı çalışmalarla uyumlu gözükmektedir (4, 12, 13, 28, 29). Ayrıca, bildiğimiz kadarıyla bu çalışma bir Türkiye popuplasyonunda BDNF genindeki Val66Met polimorfizmi ile obezite arasındaki ilişkiyi araştıran ilk çalışma niteliğindedir.

Bu çalışmanın bir limitasyonu her ne kadar yüze yakın olsa da çalışılan olgu ve kontrol sayıları olarak düşünülebilir. Bu açıdan bu çalışma ileriki çalışmalar için bir pilot tarama çalışması niteliğinde kabul edilebilir.

Sonuç olarak, biz bu çalışmada bir Türkiye populasyonunda erişkinlerde ilk defa BDNF Val66Met polimorfizmi ile obezite arasında ilişki olup olmadığını çalıştık ve herhangi bir ilişki bulunmadı. Elde edilen veriler ışığında çalışılan erişkin Türkiye populasyonunda BDNF Val66Met polimorfizminin obezite patogenezinde rol oynadığına dair bir bulguya rastlanmamıştır. BDNF Val66Met polimorfizminin obezitedeki rolünü netleştirmek için daha yüksek sayılı hem Türkiye içi ve hem de başka populasyonlarda ileri genetik ve işlevsel çalışmalara intiyaç duyulduğu kanaatine varılmıştır.

\section{KAYNAKLAR}

1. Kernie SG, Liebl DJ, Parada LF. BDNF regulates eating behavior and locomotor activity in mice. EMBO J 2000;19(6):1290-300.

2. Rios M, Fan G, Fekete $C$, et al. Conditional deletion of brain-derived neurotrophic factor in the postnatal brain leads to obesity and hyperactivity. Mol Endocrinol 2001;15(10):1748-57.

3. Lyons WE, Mamounas LA, Ricaurte GA, et al. Brainderived neurotrophic factor-deficient mice develop aggressiveness and hyperphagia in conjunction with brain serotonergic abnormalities. Proc Natl Acad Sci U S A 1999;96(26):15239-44. 
4. Friedel S, Horro FF, Wermter AK, et al. Mutation screen of the brain derived neurotrophic factor gene (BDNF): identification of several genetic variants and association studies in patients with obesity, eating disorders, and attention-eficit/hyperactivity disorder. Am J Med Genet B Neuropsychiatr Genet 2005;132B(1):96-99.

5. Gray J, Yeo GS, Cox JJ, et al. Hyperphagia, severe obesity, impaired cognitive function, and hyperactivity associated with functional loss of one copy of the brainderived neurotrophic factor (BDNF) gene. Diabetes 2006;55(12):3366-71.

6. Gray J, Yeo G, Hung C, et al. Functional characterization of human NTRK2 mutations identified in patients with severe early-onset obesity. Int J Obes (Lond) 2007;31(2):359-64.

7. Yeo GS, Connie Hung CC, Rochford J, et al. A de novo mutation affecting human TrkB associated with severe obesity and developmental delay. Nat Neurosci 2004;7(11):1187-9.

8. Ribasés $M$, Gratacòs $M$, Armengol $L$, et al. Met66 in the brain-derived neurotrophic factor (BDNF) precursor is associated with anorexia nervosa restrictive type. Mol Psychiatry 2003;8(8):745-51.

9. Ribasés $M$, Gratacòs $M$, Fernández-Aranda $F$, et al. Association of BDNF with anorexia, bulimia and age of onset of weight loss in six European populations. Hum Mol Genet 2004;13(12):1205-12.

10. Ribasés $M$, Gratacòs $M$, Fernández-Aranda $F$, et al. Association of BDNF with restricting anorexia nervosa and minimum body mass index: a family-based association study of eight European populations. Eur J Hum Genet 2005;13(4):428-34.

11. Beckers S, Peeters A, Zegers D, Mertens I, Van Gaal L, Van Hul W. Association of the BDNF Val66Met variation with obesity in women. Mol Genet Metab 2008;95(12):110-2.

12. Nikolac Perkovic M, Mustapic M, Pavlovic M, et al. Lack of association between brain-derived neurotrophic factor Val66Met polymorphism and body mass index change over time in healthy adults. Neurosci Lett 2013;545:12731.

13. Zegers $D$, Hendrickx R, Verrijken A, et al. Screening for genetic variants in BDNF that contribute to childhood obesity. Pediatr Obes 2014;9(1):36-42.

14. Mollaoğlu H, Üçok $K$, Akgün L, Baş O. Biyoelektrik empedans analizi ve antropometrik yöntemlerle ölçülen vücut yağ yüzdelerinin karşılaştırılması. Kocatepe Tıp Derg 2006;7(2):27-31.

15. American College of Sports Medicine (ACSM). ACSM's health-related physical fitness assessment manual. 2nci Baskı, Baltimore: Lippincott Williams \& Wilkins, 2007:4857.

16. Huang $T L$, Lee CT. Associations between brainderived neurotrophic factor G196A gene polymorphism and clinical phenotypes in schizophrenia patients. Chang Gung

Med J 2007;30(5):408-13.

17. Xu B, Goulding EH, Zang $K$, et al. Brain-derived neurotrophic factor regulates energy balance downstream of melanocortin-4 receptor. Nat Neurosci 2003;6(7):736-42.

18. International HapMap Project. www.hapmap.org.

19. Egan MF, Kojima M, Callicott JH, et al. The BDNF val66met polymorphism affects activity-dependent secretion of BDNF and human memory and hippocampal function. Cell 2003;112(2):257-69.

20. Chen ZY, Patel PD, Sant G, Meng CX, Teng KK, Hempstead BL, Lee FS. Variant brain-derived neurotrophic factor (BDNF) (Met66) alters the intracellular trafficking and activity-dependent secretion of wild-type BDNF in neurosecretory cells and cortical neurons. J Neurosci 2004;24(18):4401-11.

21. Oroszi G, Lapteva $L$, Davis $E$, et al. The Met66 allele of the functional Val66Met polymorphism in the brainderived neurotrophic factor gene confers protection against neurocognitive dysfunction in systemic lupus erythematosus. Ann Rheum Dis 2006;65(10):1330-5.

22. Lee $R$, Kermani $P$, Teng KK, Hempstead BL. Regulation of cell survival by secreted proneurotrophins. Science 2001;294(5548):1945-8.

23. Gunstad J, Schofield P, Paul RH, et al. BDNF Val66Met polymorphism is associated with body mass index in healthy adults. Neuropsychobiology 2006;53(3):153-6.

24. Shugart YY, Chen L, Day IN, et al. Two British women studies replicated the association between the Val66Met polymorphism in the brain-derived neurotrophic factor (BDNF) and BMI. Eur J Hum Genet 2009;17(8):1050-5.

25. Skledar M, Nikolac M, Dodig-Curkovic K, Curkovic $M$, Borovecki F, Pivac N. Association between brain-derived neurotrophic factor Val66Met and obesity in children and adolescents. Prog Neuropsychopharmacol Biol Psychiatry 2012;36(1):136-40.

26. Hong KW, Lim JE, Go MJ, et al. Recapitulation of the association of the Val66Met polymorphism of BDNF gene with BMI in Koreans. Obesity (Silver Spring) 2012;20(9):1871-5.

27. Ma XY, Qiu WQ, Smith $C E$, et al. Association between BDNF rs6265 and obesity in the Boston Puerto Rican Health Study. J Obes 2012;2012:102942.

28. Marti A, Santos JL, Gratacos $M$, et al. Association between leptin receptor (LEPR) and brain-derived neurotrophic factor (BDNF) gene variants and obesity: a case-control study. Nutr Neurosci 2009;12(4):183-8.

29. Arija V, Ferrer-Barcala M, Aranda N, Canals J. BDNF Val66Met polymorphism, energy intake and BMI: a followup study in schoolchildren at risk of eating disorders. BMC Public Health 2010;10(sayı yok):363. 